\title{
VICENTE BLASCO IBÁÑEZ Y LA MEMORIA DE CERVANTES EN ARGEL
}

\author{
Karima AÏt Yahia \\ Universidad de Argel
}

\begin{abstract}
Resumen
Hacia finales del siglo xix surgió una nueva interpretación nacionalista de la obra de Miguel de Cervantes. Benito Pérez Galdós, por ejemplo, afirmó después del Desastre de 1898 y la pérdida de las últimas colonias que Don Quijote de la Mancha era uno de los pocos objetos de orgullo nacional que le quedaban a España. En este sentido, en 1905 se celebró a lo grande el tercer centenario de la publicación de la obra maestra de Cervantes. Un escritor que se adelantó a esta nueva interpretación fue Vicente Blasco Ibáñez, quien viajó a Argelia en 1895. En sus Crónicas de viaje, describió con mucho detalle su visita a la cueva de Cervantes en Argel, donde rindió homenaje a su héroe literario. Al mismo tiempo, lamentó la falta de reconocimiento por parte de la población local y las autoridades francesas y españolas.
\end{abstract}

Palabras clave: Miguel de Cervantes, Vicente Blasco Ibáñez, Cueva de Cervantes, Argel, nacionalismo.

\begin{abstract}
Towards the end of the nineteenth century, a new nationalist interpretation emerged of the oeuvre of Miguel de Cervantes. After the disastrous defeat in the Spanish-American War of 1898 and the loss of Spain's last colonies, Benito Pérez Galdós, for instance, asserted that Don Quixote was one of the few remaining objects of national pride. In this sense, in 1905 the third centennial of the publication of Cervantes' masterpiece was celebrated in grand style. A writer that anticipated this new interpretation was the young Spanish novelist Vicente Blasco Ibáñez, who in 1895 travelled to Algeria. In his Crónicas de viaje, he described in great detail his visit to the cave of Cervantes in Algiers, where he paid tribute to his literary hero. At the same time, he deplored the lack of recognition of Cervantes by the local population and the French and Spanish authorities.
\end{abstract}

Keywords: Miguel de Cervantes, Vicente Blasco Ibáñez, Cave of Cervantes, Algiers, Nationalism.

\section{LA NACIONALIZACIÓN DE CERVANTES}

Durante el siglo XIX se dio una nueva interpretación y lectura a la obra El ingenioso hidalgo Don Quijote de la Mancha de Miguel de Cervantes y 
Saavedra. Fueron los escritores alemanes los primeros en dar una interpretación romántica a la obra de Cervantes. Ese fue el caso por ejemplo de Friedrich Schlegel, que vio en Don Quijote un héroe romántico que simbolizaba la lucha entre los ideales y la realidad y equiparó Cervantes con Shakespeare y Goethe ${ }^{1}$. De igual forma, los escritores ingleses y franceses adoptaron una nueva postura ante esta obra maestra, al verla como la primera novela moderna, lo que a su vez repercutió en los autores y cervantistas españoles a partir de la tercera década del siglo XIX ${ }^{2}$.

Mientras que en el siglo Xviı algunos autores españoles seguían dudando de las cualidades literarias y morales de la gran novela de Cervantes, en el siglo XIX, gracias en gran parte a su nueva fama internacional, el autor era aceptado en España como uno de los escritores más grandes de todos los tiempos. El principal tema que preocupaba a los escritores e intelectuales españoles era cómo había que interpretar la obra maestra de Cervantes. Por ejemplo, el periodista Nicolás Díaz de Benjumea opinaba en un libro sobre el desencanto del Quijote, publicado en I86I, que la novela contenía muchos mensajes ocultos que hacían referencia a la vida personal de Cervantes. Su obra también era una sátira feroz de la sociedad de su tiempo, criticando sobre todo a la Inquisición ${ }^{3}$. Juan Valera no estaba de acuerdo con esta interpretación rebuscada. Según el gran novelista, Don Quijote era un libro cómico, una parodia genial de los libros de caballerías y nada más ${ }^{4}$.

Hacia finales del siglo XIX, ya no importaba tanto la interpretación exacta del contenido del libro, sino el propio Cervantes y su Quijote, que se convirtieron en símbolos nacionales ${ }^{5}$. Tras la derrota humillante en la guerra contra los Estados Unidos, en la cual España perdió sus últimas

1 Anthony Close, La concepción romántica del Quijote, Barcelona, Crítica, 2005, pp. 55-71 y 8990; José Montero Reguera, El Quijote durante cuatro siglos. Lecturas y lectores, Valladolid, Universidad de Valladolid, 2005, p. 46

2 Alberto Navarro, "Introducción”, en Miguel de Unamuno, Vida de Don Quijote Y Sancho, Madrid, Cátedra, pp. 13-131, esp. pp. 42-55.

3 Diego Martínez Torrón, “La polémica cervantina de Díaz Benjumea”, en Diego Martínez Torrón (coord.), Sobre Cervantes, Alcalá de Henares, Centro de Estudios Cervantinos, 2003, pp. 115-129.

4 Navarro, ob. cit., pp. 48-50.

5 Friedrich Wolfzettel, “De símbolo nacional a mito literario de la nación. Funciones del Quijote en España entre el romanticismo y la generación de 1898”, en Sarah de Mojica y Carlos Rincón (coord.), Lectores del Quijote, 1605-2005, Bogotá, Pontificia Universidad Javeriana, 2004, pp. 61-99. 
colonias, la obra maestra de Cervantes se había convertido, según Benito Pérez Galdós, en el principal objeto de orgullo nacional. Sin embargo, el famoso autor realista se quejó de que Cervantes solo había sido honrado con una miserable estatua en la Plaza de las Cortes ${ }^{6}$. Pocos años después, algunos intelectuales liberales y republicanos decidieron hacer caso a Galdós, organizando una conmemoración nacional del tercer centenario de la publicación de Don Quijote en 1905, para así honrar al escritor en todo el territorio nacional. El 2 de diciembre de I903, el periodista Mariano de Cavia lanzó la iniciativa en la portada del diario El Imparcial bajo el lema "Post tenebras spero lucem". Hizo un llamamiento a celebrar "la más luminosa y esplendorosa fiesta que jamás ha celebrado pueblo alguno" para superar las "presentes desdichas" de España ${ }^{7}$.

Durante la conmemoración, Juan Valera y el erudito conservador Marcelino Menéndez Pelayo repitieron que había que comprender la novela de Cervantes como un libro cómico y entretenido, donde Cervantes criticaba de manera indulgente los libros de caballerías de su tiempo. Sin embargo, la mayoría de los conferenciantes - entre los cuales se encontraban el político liberal José Canalejas, el médico Santiago Ramón y Cajal y el escritor republicano Jacinto Octavio Picón- veía a Cervantes como un gran héroe nacional que ponía todos sus talentos y fuerzas al servicio de la patria. Había luchado como soldado en Lepanto. Y como escritor se esforzó, al máximo, por construir el patrimonio literario de la patria. De la misma forma, los españoles de aquel entonces tenían que seguir su ejemplo, luchando contra la resignación y la ignorancia a favor del progreso intelectual y material de su país ${ }^{8}$. Los autores de la Generación de I898 se identificaban plenamente con Don Quijote y lo convirtieron en un símbolo nacional. Azorín, por ejemplo, publicó su Ruta de Don Quijote en la primavera de 1905, donde describió las emociones que sentía siguiendo las huellas del héroe de la novela en La Mancha. Miguel de Unamuno se identificó incluso plenamente con la existencia

6 Benito Pérez Galdós, “Cervantes”, en Vida Nueva, 1898, 30 de octubre y 6 de noviembre; véase también Eric Storm, La perspectiva del progreso. Pensamiento político en la España del cambio de siglo (1890-1914), Madrid, Biblioteca Nueva, 2001, p. 291.

7 Mariano de Cavia, "El centenario del 'Quijote”, El Imparcial, 1903, 2 de diciembre.

8 Eric Storm, "El tercer centenario del Don Quijote en 1905 y el nacionalismo español”, Hispania. Revista Española de Historia, 1998, vol. 58, núm. 199, pp. 625-655. 
trágica de Don Quijote. En su libro Vida de Don Quijote y Sancho (I905), afirmó que el afán de inmortalidad, que según él era la gran filosofía del Quijote, también era característico del pueblo español ${ }^{9}$. De esta manera, intelectuales y escritores del fin de siglo vieron en Don Quijote de la Mancha la obra más "nacional" que se había escrito en la historia de España.

Desde entonces, Cervantes y Don Quijote se mantuvieron presentes en el centro del debate público. En i9ı6, por ejemplo, se celebró el tercer centenario de la muerte de Cervantes. Para esa ocasión se hicieron planes para construir un nuevo monumento a Cervantes y su obra maestra en la Plaza de España de Madrid. Aquel monumento tenía que reflejar la inmensa importancia del escritor y de la figura de Don Quijote para la cultura española. Aunque al final hubo muchos retrasos, y se terminó por inaugurar en 1929, esta vez sí que fue un monumento digno y grandioso. Además, en 1920, el gobierno decretó que era obligatorio leer la novela de Cervantes en las aulas de todas las escuelas de la nación, consagrando así un largo proceso de glorificación nacional ${ }^{10}$.

Otro autor destacado de la época que no escondió su admiración por Cervantes fue Vicente Blasco Ibáñez, que mostró tal fascinación por el gran autor del Siglo de Oro que escribiría hacía el final de su carrera un guión cinematográfico sobre la vida del Quijote ${ }^{11}$. A principios de los años noventa del siglo xIx, Blasco Ibáñez hizo dos viajes a Argel, donde Cervantes había estado preso entre 1575 y 1580 . En una de las crónicas de viaje que publicó en I895, titulada "La cueva de Cervantes", encontramos una exaltación de Cervantes que se asemeja mucho a las interpretaciones nacionalistas que se podían escuchar durante el tricentenario de Don Quijote en 1905. En este sentido, cabe preguntarse si Blasco Ibáñez se adelantó a la nueva interpretación nacionalista de Cervantes y su obra maestra. Por consiguiente, pretendemos hacer un análisis detallado de su artículo sobre Cervantes, situándolo en el contexto concreto de su viaje a Argelia.

9 Storm, ob. cit., 1998, pp. 645-649; Navarro, ob. cit., pp. 75-110.

10 Jean-Louis Guereña, “¿Un icono nacional? La instrumentalización del Quijote en el espacio escolar en el primer tercio del siglo xix”, Bulletin Hispanique, 2008, vol. CX, núm. 1, pp. 145-190; Javier Moreno Luzón, "Una fiesta de todos: 23 abril, culto a Cervantes y día del libro", Ariadne histórica. Lenguajes, conceptos, metáforas, 2009, vol. VIII, pp. 107-131.

11 Emilio José Salas Dasí, "La lectura cervantina de Blasco Ibáñez” en Vicente Blasco Ibáñez, Don Quijote (guion cinematográfico), Madrid, Biblioteca Nueva, 2015, pp. 25-36. 


\section{El Viaje DE BLASCO IBÁÑEZ}

Blasco Ibáñez nació en el año 1867 en Valencia. Era de una familia conservadora, estudió Derecho en la universidad de su ciudad natal y durante su carrera iba a tertulias literarias donde conoció a Constantí Lombart, la gran figura de la Renaixença valenciana. Lombart era un republicano federal radical que influyó mucho en Blasco Ibáñez ${ }^{12}$. Tras obtener su licenciatura en I888, Blasco Ibáñez comenzó a publicar un periódico semanal titulado La Bandera Federal, donde plasmaba sus ideas federalistas cercanas a las de Francisco Pi y Margall, uno de los expresidentes de la Primera República. Además, Blasco Ibáñez era anticlerical, quería acabar con los favores a la Iglesia y adoptar una política progresista en España ${ }^{13}$. Con la subida al poder de Cánovas del Castillo en I89o, su diario organizó una manifestación enorme y movilizó a las masas valencianas, lo que llevó a la policía a que intentara arrestarle. Blasco Ibáñez fue ayudado por los manifestantes y un amigo pescador lo escondió en la playa para luego transportarle en barco a Argel, desde donde más tarde se marchó a Francia ${ }^{14}$.

A su vuelta a Valencia, continuó con éxito su carrera de político republicano, movilizando a las masas locales, mientras que al mismo tiempo empezó a publicar sus primeras novelas, como Arroz y Tartana (1894). En mayo de 1895, hizo un segundo viaje a Argel en un barco de contrabando, que le serviría de inspiración para su novela Flor de Mayo (1895) ${ }^{15}$. A su llegada a Argel empezó a describir sus experiencias en unas crónicas de viaje. En total escribió siete crónicas y entre ellas encontramos "La cueva de Cervantes" ${ }^{\prime 16}$. Poco después, sus impresiones de viaje vieron la luz en

12 Ramiro Reig, Vicente Blasco Ibáñez, Madrid, Espasa, 2002, pp. 21-23; Vicente R. Alós Ferrando y Carmen Castellet Alemany, Vicente Blasco Ibáñez político, Valencia, Diputación de Valencia, 1998, pp. 13-24.

13 Reig, ob. cit., p. 30.

14 Reig, ob.cit. p. 32; Federico Lara Peinado, "Vicente Blasco Ibáñez (1867-1928): Viaje por Oriente y Egipto”, Arbor, 2005, vol. CLXXX, núm. 711-712, pp. 869-891.

15 José Vicente Boira Maiques y Julio de la Llave Cuevas, "Geografía, espacio social e imágenes de marca. El análisis de 'Flor de mayo' de Vicente Blasco Ibáñez”, Cuadernos de Geografía, 1988, vol. 43, pp. 83-105.

16 José Luis León Roca, Vicente Blasco Ibánéez, Valencia, Ajuntament de València, 2002, pp. 144-145. 
el diario republicano El Pueblo y al año siguiente los textos se integraron en una edición de Los cuentos valencianos ${ }^{17}$.

Lo que llama la atención es que, en el caso de Blasco Ibáñez, la exaltación nacionalista de Cervantes se produjo en un contexto imperial. Durante su estancia en Argelia, el autor estaba muy impresionado por la obra "civilizadora" de la Tercera República francesa en esta parte del norte de África. Implícitamente comparaba el poderío francés y su política progresista con la decadencia de España que, según él, había perdido gran parte de su Imperio y prestigio internacional por ser un régimen monárquico corrupto, atrasado y religiosamente muy conservador. Al igual que Pérez Galdós y Cavia, Blasco Ibáñez pensaba que la mayor gloria que le quedaba a España a estas alturas era la obra de Cervantes, que precisamente era celebrada en el mundo entero.

En el vapor Pérez, en el que viajaba Vicente Blasco Ibáñez rumbo a Argelia, el autor empezó a hablar de esta parte del Magreb como de un país vecino que muy pocos españoles conocían. Lo describió como parte de un misterioso continente y con el cual existían muy pocas relaciones, aparte de "la barca del contrabandista que bordea su costa esperando el alijo" o el fugitivo que huye de la justicia europea y se busca un refugio ahi ${ }^{18}$.

Ya durante su viaje en barco se refería de manera indirecta a Cervantes cuando abordó el tema de "la piratería argelina", al comparar "las galeotas de los piratas" con "buitres" e imaginar que "un brutal negrote" daba látigos a los esclavos europeos que se capturaban, tanto en alta mar como en las costas españolas, para después venderlos como esclavos en el mercado de Argel $^{19}$. Luego mantuvo que, gracias a las fuerzas navales francesas, se puso fin "al poderío musulmán en Argel, nido de piratas que Europa no podía consentir en sus mismas puertas"20. Por lo tanto, veía en

17 Emilio José Salas Dasí y Juan Carlos Pantoja Rivero en Vicente Blasco Ibáñez, Crónicas de viaje: Gibraltar, Argel, Toledo, El Escorial (edición de Emilio José Salas Dasí y Juan Carlos Pantoja Rivero), Barcelona, Carena, 2011, p. 43; Djamel Latroch, "Argel en 1895, visto por el novelista Vicente Blasco Ibáñez”, Hesperia. Culturas del Mediterráneo, 2015, pp. 85-100, esp. p. 88.

18 Vicente Blasco Ibáñez, Crónicas de viaje en Obras completas, Madrid, Aguilar, 1987, pp. 1081-1183, esp. p. 1118.

19 Ibid.pp. 1119-1120.

20 Ibid.p. 1120. 
la conquista de Argelia por Francia, en I830, un avance de la civilización europea en el Mediterráneo.

Su llegada al puerto le recordó una vez más el Argel de Barbarroja. En este sentido, afirmó que: "Los yachts y barcos de guerra anclados en el puerto parecen en la sombra galeras berberiscas prontas a darse a la mar para la caza de esclavos" ${ }^{21}$. Durante su visita a la ciudad de Argel, Blasco Ibáñez se interesó por la población indígena, sus costumbres, la arquitectura de la ciudad, los santos, los rituales musulmanes y también por el modo de vestir de los indígenas, que contrastaba con la moda europea.

Por una parte, el autor mostró gran admiración por la ciudad de Argel, por sus bulevares, como el Boulevard de la República, y sus transeúntes le recordaban París. Resaltó y alabó su libertad de cultos y la separación entre la religión y el Estado, sobre todo cuando visitó la mezquita principal de la ciudad ${ }^{22}$. Por otra parte, describió a los "indígenas" como primitivos, sucios, ruidosos y hasta repugnantes ${ }^{23}$. De esta manera, resaltó su fascinación por la Tercera República francesa y lo que "trajo" como civilización moderna a esta parte del Magreb.

Estando en esta ciudad, Blasco Ibáñez necesitaba también algo que le recordara España. Para él, la cueva de Cervantes era algo que representaba "la patria y sus glorias". El autor había leído que "se habia elevado una estatua a Cervantes en la misma cueva donde el sublime ingenio estuvo escondido con trece compañeros de cautiverio, esperando oportunidad para escapar de la esclavitud berberisca" ${ }^{24}$. Además, pensaba que no siempre se presentaban oportunidades para ver "los lugares donde los grandes hombres han sufrido terribles desdichas, amarguras tal vez no compensadas por el respeto y el aplauso que les tributan las generaciones subsiguientes" ${ }^{25}$. Además de ser un gran admirador de Cervantes, Blasco Ibáñez se sentía identificado con él porque también había sido encarcelado varias veces, tal y como lo afirman Emilio José Salas Dasí y Juan Carlos Pantoja Rivero ${ }^{26}$.

21 Ibid.p. 1121.

22 Ibid. pp. 1123 y 1133-1134.

23 Ibid.pp. 1135 y 1142.

24 Ibid.p. 1126.

25 Ibid.p. 1126.

26 Salas Dasí y Pantoja Rivero en Blasco Ibáñez, ob.cit. 2011, p. 100. 
La búsqueda de la gruta fue complicada para el escritor valenciano. La gente a la que encontraba en el camino desconocía totalmente a este genio de la literatura española y universal. Ante este hecho, mostró una gran decepción:

Sentíamos tristeza ante ignorancia tan general. Más que no encontrar la famosa cueva, nos apesadumbraba ver que había en Argel quien ignoraba que una gran parte de la celebridad de la población es debida a haber tenido en sus mazmorras un infeliz esclavo español llamado Miguel, que, hambriento, haraposo y quebrantado por los malos tratos, llevaba dentro de su cráneo algo que había de convertirse en el más famoso libro que admira el mundo ${ }^{27}$.

El guardián del sitio era un español de Menorca, pero apenas tenía conocimientos de los méritos de Cervantes. Al entrar en la cueva, Blasco Ibáñez observó una "lápida de bronce" que recordaba la "visita del almirante y la oficialidad de la escuadra española”. En el centro de la cueva se encontraba el busto de mármol lleno de polvo que el guardián empezó a limpiar con "un pañuelo de hierbas", lo que llevó el autor a pensar que aquella visita era quizá la primera desde la visita oficial del almirante ${ }^{28}$.

Estando ahí, imaginaba la dura estancia de Cervantes, quien en tiempos pasados había sido un distinguido "héroe" en Lepanto y que después de descubrir su escondite, sufrió "los tremendos golpes de sus conductores" ${ }^{29}$, así como "el desprecio y los insultos" de sus carceleros ${ }^{30}$. En este sentido dijo:

Creía ver a Cervantes con sus compañeros, amontonados en el fondo de la gruta durante el día, temblando de inquietud al menor ruido que viniese de fuera; saliendo por la noche cautelosamente, arrastrándose como culebras para robar en los inmediatos huertos algo con que sostener sus fuerzas ... y el momento en que, descubierto el refugio de los fugitivos esclavos, caía sobre ellos el tropel de feroces argelinos de negros hercúleos y los encadenaban como a fieras, conduciéndoles otra vez a las mazmorras

27 Blasco Ibáñez, ob. cit., 1987, p. 1126.

28 Ibid.p. 1128.

29 Ibid.p. 1128.

30 Ibid.p. 1129. 
de Argel ... sufriendo antes en el camino los insultos de la curiosa chusma y los tremendos golpes de sus conductores ${ }^{31}$.

Al final de su visita a la cueva, el autor imaginaba cómo, mientras Cervantes sufría la tortura de sus carceleros, le venía la inspiración de lo que se convertiría en "la mayor joya literaria"32 y se quejaba de que "después de tres siglos de gloria, de formar la más luminosa de las trinidades con Dante y Shakespeare, de haber enriquecido el patrimonio del mundo con Don Quijote", se ignoraba el sitio donde más había sufrido y que el guardián del sitio no sabía casi nada acerca de este gran hombre de letras, excepto que "Conten quera un hóme molt chistós que tenía partit entre los dónes. La Filla del rey d'Alger estaba enamorada d'ell y li salvá la vida" ${ }^{3}$. De esta manera, su visita a la gruta fue por un lado impresionante porque le recordaba todo lo que pudo pasar ahí y, por otro, decepcionante por el estado en que se encontraba el sitio.

Esta admiración por la obra y la persona de Cervantes le acompañaría durante el resto de su carrera, puesto que visitaría después otros lugares relacionados con la memoria del autor de Don Quijote. Además, los escritos cervantinos constituyeron un "estímulo" duradero para su propia obra literaria ${ }^{34}$.

\section{Conclusión}

Está claro que uno de los ejes que estructuran el texto de Blasco Ibáñez es la lucha entre la civilización y la barbarie, que para él constituía una preocupación fundamental con respecto a España. Como republicano, quería regenerar el país, combatir el retraso, la falta de cultura y convertir España en un país moderno. La Tercera República francesa era el ejemplo a seguir. Esto se puso de manifiesto en sus descripciones de Argelia, donde alababa todo lo que era francés. Sin embargo, esta contradicción de barbarie y civilización también está muy presente en la descripción de su visita a la cueva de Cervantes. Junto a Shakespeare y Dante, Cervantes era uno de los grandes genios de la literatura universal de todos

31 Ibid.p. 1129.

32 Ibid.p. 1129.

33 Ibid.p. 1129.

34 Salas Dasí, op.cit., 2015, p. 27. 
los tiempos. A través de su obra maestra, Don Quijote de la Mancha, creó un hito de la literatura española y de la cultura europea. Sin embargo, él también fue víctima de la barbarie; en este caso, de los piratas argelinos que le habrían convertido en esclavo si no fuera, según él, por la escuadra francesa que había puesto fin a estas prácticas atrasadas.

La falta de cultura seguía siendo un problema, ya que Cervantes había caído en el olvido. En Argel, nadie le conocía o visitaba la cueva, aunque España le había rendido homenaje poco antes levantado un busto y poniendo una lápida en ella. El guardián era un hombre inculto que solo sabía decir disparates sobre la supuesta vida amorosa del gran escritor. Blasco Ibáñez, no obstante, le rindió homenaje y le dedicó una gran parte de sus notas de viaje. Si España volviera a inspirarse en este gran héroe literario, podría renacer y volver a jugar un importante papel en la cultura moderna.

De esta manera, Blasco Ibáñez se adelantó claramente al renacimiento que conocería la memoria de Cervantes después de la pérdida de las últimas colonias y el Desastre de i898. Benito Peréz Galdos concluyó que después de la caída del Imperio Español, Cervantes era la última gloria que le quedaba a España. Por lo tanto, liberales y republicanos tomaron la iniciativa de celebrar por todo lo alto el tercer centenario de la publicación del Quijote, en 1905, que fue una fiesta nacional de dimensiones desconocidas hasta entonces. Su fin era regenerar el país del estado de decadencia en el cual se encontraba. La manera en la que Blasco Ibáñez presentó a Cervantes era muy parecida a la de escritores progresistas como Galdós y Cavia. Estos no se preocupaban por la interpretación exacta de la novela, ni se identificaban con su protagonista, como sí lo harían Azorín y Unamuno durante el centenario, sino por el propio autor de la novela. Como aquellos, Blasco Ibáñez hacía más bien hincapié en los sufrimientos que tuvo que soportar Cervantes y en lo poco que se le reconocía.

En I920, cuando el gobierno español decidió finalmente hacer obligatoria la lectura del Quijote en una versión adaptada para todas las escuelas primarias con el fin de regenerar el país, Blasco Ibáñez, que para entonces se había convertido en un escritor de fama internacional, seguramente apoyaría la medida. 